\title{
PEBA: A ARTE E A PESQUISA EM EDUCAÇÃO
}

\author{
Carla Carvalho ${ }^{1}$ \\ Charles Immianovsky²
}

\section{Resumo}

Este artigo tem como temática central a perspectiva metodológica conhecida como Pesquisa Educacional Baseada em Arte (PEBA). Contextualiza-se a PEBA no campo da pesquisa e da pesquisa em Educação, apresentam-se os aspectos epistemológico-metodológicos que a caracterizam (HERNÁNDEZ, 2013; DIAS, 2013; IRWIN, 2013a; OLIVEIRA, 2013; BARONE; EISNER, 2006) e as implicações dessa perspectiva para pesquisa na área da Educação. Ainda, o texto aprofunda a temática ao abordar a A/r/tografia, um dos métodos da PEBA. Quanto à A/r/tografia, localizam-se os pontos de referência dos estudos no âmbito internacional e nacional, seu campo epistemológico e metodológico e as implicações da prática a/r/tográfica no contexto da PEBA (DIAS, 2013; IRWIN, 2013a, 2013b; HERNÁNDEZ, 2013; OLIVEIRA, 2013; TOURINHO, 2013a, 2013b). Além de fornecer subsídio teórico para a compreensão das características e das implicações dessa metodologia para a pesquisa em educação, este trabalho demonstra que a PEBA tem atraído o olhar de estudiosos interessados em novas metodologias de pesquisa e, se desenvolvido principalmente por meio da A/r/tografia, é um dos métodos da PEBA já sistematizados.

Palavras-chave: Pesquisa; Educação; PEBA; A/r/tografia

\section{ABER: ART AND RESEARCH IN EDUCATION}

\footnotetext{
${ }^{1}$ Doutora em Educação pela Universidade Federal do Paraná. Professora no Programa de Pós-Graduação em Educação na Universidade Regional de Blumenau (FURB). E-mail: ca_carvalho@icloud.com

${ }^{2}$ Mestre em Educação pela Universidade do Vale do Itajaí. Professor no Instituto Federal Catarinense - Campus Luzerna. E-mail: ismirnov_arte@hotmail.com
} 


\begin{abstract}
This paper has as central theme the methodological perspective known as Art Based Education Research (ABER). We contextualize ABER in the field of research and research in Education, we present the epistemological-methodological aspects that characterize it (HERNÁNDEZ, 2013; DIAS, 2013; IRWIN, 2013a; OLIVEIRA, 2013; BARONE; EISNER, 2006) and the implications of this perspective for research in the area of Education. Furthermore, the text goes deeper into the theme when addressing the $\mathrm{A} / \mathrm{r} /$ tography, one of the ABER methods. In relation to the $\mathrm{A} / \mathrm{r} /$ tography, we locate the reference points of studies in the international and national levels, their epistemological and methodological field, and the implications of the $\mathrm{a} / \mathrm{r} / \mathrm{tog}$ raphic practice in the context of ABER (DIAS, 2013; IRWIN, 2013a, 2013b; HERNÁNDEZ, 2013; OLIVEIRA, 2013; TOURINHO, 2013a, 2013b). In addition to providing theoretical support for the understanding of the characteristics and implications of this methodology for research in education, this work demonstrates that ABER has attracted the attention of scholars interested in new research methodologies and, if developed mainly through $\mathrm{A} / \mathrm{r} /$ tography, is one of the ABER methods already systematized.
\end{abstract}

Keywords: Research; Education; ABER; A/r/tography

\title{
PEBA: EL ARTE Y LA INVESTIGACIÓN EN EDUCACIÓN
}

\section{Resumen}

Este artículo tiene como temática central la perspectiva metodológica conocida como Investigación Educativa Basada en Arte (PEBA). Se contextualiza la PEBA en el campo de la investigación y de la investigación en Educación, se presentan los aspectos epistemológicos-metodológicos que la caracterizan (HERNÁNDEZ, 2013; DIAS, 2013; IRWIN, 2013 ; OLIVEIRA, 2013; BARONE; EISNER, 2006) y las implicaciones de esta perspectiva para la investigación en el área de la Educación. También, en el texto se profundiza la temática al abordar la A/r/tografía, uno de los métodos de la PEBA. En cuanto a la a/r/tografía, se localizan los puntos de referencia de los estudios en el ámbito internacional y nacional, su campo epistemológico y metodológico y las 
implicaciones de la práctica a/r/tográfica en el contexto de la PEBA (DIAS, 2013; IRWIN, 2013a, 2013b; HERNÁNDEZ, 2013; OLIVEIRA, 2013; TOURINHO, 2013a, 2013b). Además de proporcionar subsidio teórico para la comprensión de las características y de las implicaciones de esa metodología para la investigación en educación, en este trabajo se demuestra que la PEBA ha atraído la mirada de estudiosos interesados en nuevas metodologías de investigación y, si se desarrolla principalmente a través de la a/r/tografía, es uno de los métodos de la PEBA ya sistematizados.

Palabras clave: Investigación; Educación; PEBA; A/r/tografía

\section{INTRODUÇÃO}

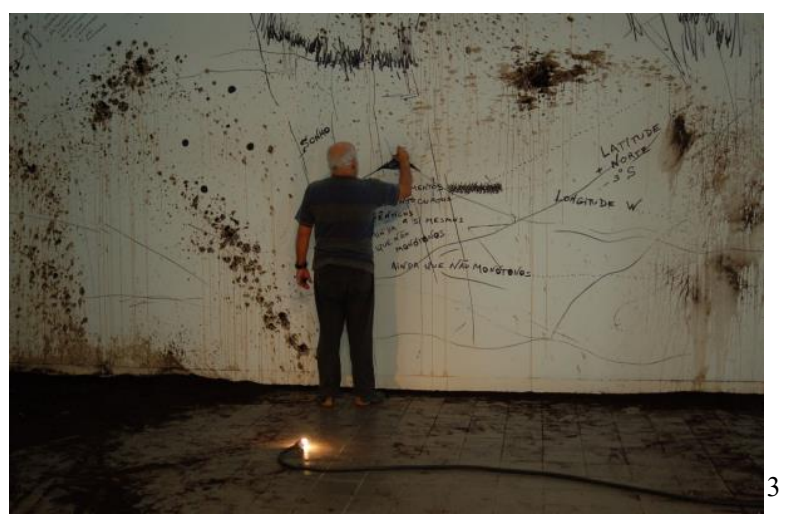

A imagem que aqui usamos como epígrafe provoca-nos a pensar não apenas sobre o produto final da arte, mas o processo como elemento fundamental na arte, na arte de nosso tempo. Talvez, ao olhar para a "História da Arte", nunca pensamos tanto sobre o processo como na contemporaneidade, de forma a deslocar o olhar do produto para o processo. Nesse sentido, elaboramos um novo discurso para a arte. Entender ou discutir arte de nosso tempo envolve a compreensão de que a estética deste tempo, da contemporaneidade, está entrecortada por elementos que não são mais fechados, canônicos, como em outros tempos marcados até a arte moderna. Buscamos nessa relação com a arte uma ligação com a pesquisa e com o processo de se fazer pesquisa em educação em arte.

\footnotetext{
${ }^{3}$ Artur Barrio, Actions after actions (Ações após ações), 2006. Disponível em: <http://moore.edu/the-galleries-atmoore/exhibitions/exhibition-history/2006/artur-bario-actions-after-actions>. Acesso em: 22 maio 2017.
} 
Se é consenso, no campo da pesquisa, que a metodologia é parte fundamental de toda investigação, seja nesta ou naquela área, menos nítido têm sido o consenso em torno da validade e da viabilidade de metodologias que utilizam modos rígidos de delineamento do processo de investigação nas Ciências Sociais e Humanas. Na Educação, a ampliação do número de pesquisas e estudos de abordagem qualitativa, ao lado das problematizações teóricas sobre o campo do conhecimento, especialmente a teorização pós-crítica, despertaram o desenvolvimento de novos procedimentos, meios e ferramentas metodológicas, promovendo delineamentos metodológicos menos rígidos para atender a contextos específicos de pesquisa. Pensar o delineamento metodológico mais como processo do que produto, mais como construção do que receita, tornouse central para alguns pesquisadores do campo da Educação.

Para além da fixidez aparentemente vinculada ao delineamento dos processos de uma pesquisa, estudos têm demonstrado e relatado o quão os modos de pesquisar podem ou são verdadeiros processos criativos individuais. ${ }^{4}$ Uma espécie de "metodologia alquimista", que traz um olhar sobre as relações entre arte e pesquisa, ou arte e ciência, ao reconhecer a capacidade de inventar ao pesquisar, confrontando os excessos de rigidez e de recomendações que tem permeado a ciência moderna, contrapondo-se à "metodolatria"6 .

Nesse contexto, pesquisadores vinculados ao campo da arte e educação têm investido nessa relação de outro modo: incorporam os próprios processos e produtos artísticos aos procedimentos e ao relato de uma investigação. Esse modo de vincular arte e pesquisa no campo da Educação corresponde à Pesquisa Educacional Baseada em Arte (PEBA).

A PEBA configura-se como perspectiva metodológica que utiliza processos e produtos artísticos, estéticos por natureza, para investigar, problematizar e compreender questões educacionais. Essa perspectiva tem se desenvolvido principalmente por meio da A/r/tografia, um dos métodos da PEBA já sistematizados, que incorpora especificamente os procedimentos e as atividades artísticas - fazer artístico - no processo de investigação.

\footnotetext{
${ }^{4}$ A respeito de novas perspectivas metodológicas adotadas em pesquisas em educação no Brasil, ler: Metodologias de pesquisas pós-críticas em educação (MEYER; PARAÍSO, 2012).

5 "A metodologia alquimista gosta do não método, da mistura, da magia, da possibilidade, do proibido, do risco" (CARDOSO, 2012, p. 219).

${ }^{6}$ Irene Tourinho (2013a) propõe-nos visualizar as metodologias como uma multiplicidade de caminhos, indo contra o que a autora chama de "metodolatria", que é um apego tão forte ao método que esse se sobressai ao próprio objeto de estudo ou ensino.
} 
Ao contextualizar a PEBA e a A/r/tografia, apresentar os aspectos epistemológicometodológicos pelos quais se fundamentam e as implicações destas para a pesquisa em educação, objetivamos fornecer subsídio teórico sobre essa perspectiva e sua contribuição e aplicação na pesquisa educacional. E, quiçá, instigar a aproximação de outros pesquisadores do campo educacional interessados em delineamentos metodológicos menos rígidos, que permita atender contextos específicos de pesquisa em Educação.

\section{A Pesquisa Educacional Baseada em Arte}

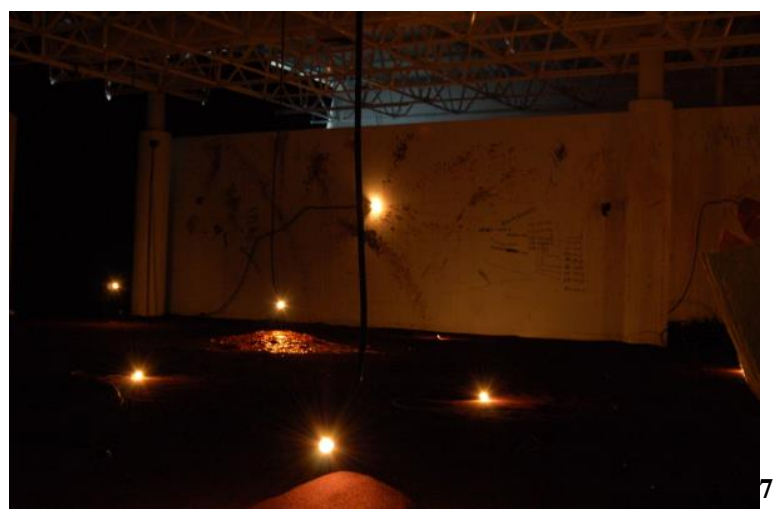

A obra de Barrio provoca-nos. Por esse motivo, percorre o texto, em detalhes, na ação, no fragmento. Assim como sua obra, o processo aqui é pensado, a pesquisa e a metodologia ganham foco, pois entendemos que a forma de fazer Pesquisa em Educação Baseada em Arte tem relação com a forma com a qual pensamos e compreendemos a arte de nosso tempo. Barrio incita-nos a pensar o lugar da arte, o sistema da arte, as condições de arte de nosso tempo, com sua visualidade, cuja gestualidade e caos ganham a centralidade.

A PEBA configura-se como uma metodologia específica para a pesquisa em educação que deriva da Pesquisa Baseada nas Artes (PBA) ou Investigación Baseada em las Artes (IBA) ${ }^{8}$ A IBA e as perspectivas que dela derivam vinculam investigação e arte a partir de uma dupla relação.

7 Imagem da instalação de Artur Barrio, Actions after actions (Ações após ações), 2006. Disponível em: <http://moore.edu/the-galleries-at-moore/exhibitions/exhibition-history/2006/artur-bario-actions-after-actions〉. Acesso em: 22 maio 2017.

${ }^{8} \mathrm{O}$ termo em espanhol Investigación Baseada em las Artes (IBA) tem seu equivalente em português em Pesquisa Baseada nas Artes (PBA), e Arts-basead Research (ABR), em inglês. 
Por um lado, a partir de uma instância epistemológica-metodológica, da qual se questiona as formas hegemônicas de investigação centradas na aplicação de procedimentos que 'fazem falar' à realidade; e por outro, por meio do uso de procedimentos artísticos (literários, visuais, performativos, musicais) para dar conta dos fenômenos e experiências que se dirigem ao estudo em questão. (HERNÁNDEZ, 2013, p. 40-41, grifo do autor).

Essas metodologias desenvolveram-se, sistematizaram-se e têm influenciado as investigações no campo das Ciências Sociais e Humanas, especialmente a partir de dois fatos: os estudos de Elliot Eisner, desenvolvidos nos anos de 1970, na Stanford University, nos Estados Unidos (IRWIN, 2013a; OLIVEIRA, 2013; DIAS, 2013); e o campo teórico denominado "virada linguística”, no princípio dos anos de 1980 (HERNÁNDEZ, 2013).

Ao utilizar a arte como elemento base para suas investigações, que tinham por propósito descrever a prática de pesquisa de críticos ligados à educação, Elliot Eisner abriu espaço para a discussão sobre a utilização da arte como metodologia de pesquisa, e não apenas como objeto de estudo. Posteriormente, esse modo de articular arte à pesquisa fortaleceu-se a partir da influência do que se denominou "virada linguística" nas Ciências Sociais. Assim a IBA/PBA é utilizada em diferentes países e aplicada a diferentes áreas como a Sociologia, a Antropologia, a Psicologia e a Educação.

Ao visualizar-se a possibilidade da IBA/PBA ser aplicada a qualquer disciplina e em conjunto a outras formas de pesquisa, fez-se visível a inserção e a contribuição dessa metodologia no campo da educação, constituindo o que se denomina PEBA. A Pesquisa Educacional em Arte é uma metodologia que pode ser compreendida como “[...] uma ampliação que reconhece a contribuição específica das PBAs para a educação" (SINNER et al., 2013, p. 102). Assim, a intenção de influenciar assuntos educacionais apresenta-se como diferença considerável entre a PEBA e outras formas de PBA/IBA.

De modo geral, a centralidade dessas perspectivas metodológicas está na utilização de procedimentos e/ou produtos artísticos no processo investigativo ou no registro deste, com objetivo de, por meio das artes, expandir a percepção sobre eventos educacionais e permitir novos entendimentos sobre o que pode contribuir em melhorias nas políticas educacionais e práticas educativas.

Investigações nessa perspectiva apropriam-se dos procedimentos artísticos a fim de dar conta de experiências e de contribuições dos sujeitos relacionados à pesquisa, que, por meio de outros métodos de investigação, não seria possível visualizar. De caráter qualitativo, a PEBA insere-se 
em uma perspectiva de pesquisa que se configura em uma instância epistemológico-metodológica, que questiona formas hegemônicas de pesquisar.

Ao questionarem formas hegemônicas de pesquisar, as formas de PBA, assim como a PEBA, estão mais preocupadas em problematizações do que com respostas fechadas, visto que os questionamentos, nesse tipo de pesquisa, pretendem estimular a imaginação, a invenção, preenchendo espaços vazios pelas tramas vivenciadas entre pesquisador, colaboradores e leitores. Borra-se a hierarquização entre esses sujeitos, uma vez que as fronteiras entre esses agentes se tornam menos visíveis na produção do conhecimento que deriva do processo de investigação. Buscam-se mais aproximações do que definições de espaços entre pesquisador, colaboradores e leitores. "Essa incorporação do leitor supõe um posicionamento radicalmente novo frente ao que se costuma entender por investigação. Um posicionamento que de fato tem a ver com os intentos de descentralização do sujeito que já aconteceu no terreno artístico.” (HERNÁNDEZ, 2013, p. 47, grifo do autor). Contudo, quais procedimentos caracterizam a PEBA e permitem a descentralização do pesquisador?

Embora os procedimentos adotados na PEBA possam ser diversos, há dois critérios essenciais que caracterizam, de modo geral, essa metodologia: relaciona-se frequentemente a um objetivo associado à atividade artística; centra-se na presença de certas qualidades estéticas ou elementos de concepção no processo de investigação e/ou na redação do texto da pesquisa (BARONE; EISNER, 2006).

Esses elementos de concepção, a atividade artística, precisam estar incorporados à pesquisa, interferindo na mecânica, no funcionamento da investigação, seja nos procedimentos adotados e/ou na redação do texto da investigação. Por isso, os elementos estéticos ou as atividades artísticas são partes indissociáveis do relato e/ou do processo da investigação.

O desafio do investigador com a PEBA não é o de utilizar ou produzir representações visuais para ilustrar o texto, por exemplo. É mais ambicioso do que isso, é “[...] tentar desenvolver paralelamente narrativas autônomas (textual e visual) que se complementem, entrecruzem e permitam que surjam espaços para criar significados e relações" (HERNÁNDEZ, 2013, p. 50).

Esses elementos estéticos podem ser adotados e utilizados em diversos momentos da investigação e, também, influenciar de diversos modos: durante a produção de dados; na forma de organizar os dados produzidos; no modo como interpretar esses dados; no(s) tipo(s) de texto(s) utilizado(s) para documentar e relatar esse processo. 
Relacionados a esses dois critérios gerais, sistematizaram-se tendências de Investigação Baseada nas Artes: a perspectiva literária, a perspectiva artística e a perspectiva performativa (HERNÁNDEZ, 2013). Na prática, essas tendências mostram que são muitas as formas possíveis de se desenvolver uma investigação no campo da Educação apropriando-se da PEBA.

A perspectiva literária trata da produção de relatos cujas diferentes formas de experiências dos sujeitos relacionados à pesquisa (colaboradores, pesquisador) são conectadas por meio de formas literárias. Nesse tipo de relato, a finalidade é conter não apenas as experiências de quem narra, mas permitir ao leitor espaços para que ele possa “incluir” suas próprias histórias. Há uma alteração na relação "investigação-investigador-leitor" - a tradicional relação díade é alterada por uma relação tríade. No limite, é “[...] contar uma história que permita a outros contar(se) a sua” (HERNÁNDEZ, 2013, p. 47, grifos do autor). Nesse sentido, é possível recorrer a diferentes gêneros textuais e formas de escrita ao se organizar os dados da investigação, de modo que a "voz" de diferentes agentes possam se fazer presentes no relato, inclusive a do leitor, por meio de aberturas, de brechas, que permitem ao leitor atuar, criar. O relato nessa perspectiva pode ser um conto, por exemplo, com a presença de narrador e personagens fictícios.

A perspectiva artística caracteriza-se, principalmente, pela incorporação de representações artísticas visuais - pinturas, fotografias, desenhos, gravuras, colagens, produções gráficas - ao texto do relato da investigação. Essas representações artísticas devem ser incorporadas ao texto verbal e não apenas ocupar um lugar de adorno no relato da investigação, uma vez que, ao ocuparem um lugar de adorno, corre-se o risco desses elementos ficarem secundarizados.

Texto verbal e visual tendem a se conectar por meio de um diálogo e não meramente na comprovação de um pelo outro. Isso significa que, sem esses elementos, não conseguiríamos ler/entender o trabalho, por isso os elementos estéticos são partes indissociáveis do texto.

Já, a perspectiva performativa centra-se na prática, na ação e na produção artística, ou seja, a produção artística não é apenas incorporada ao relato da investigação, mas é utilizada no próprio processo da investigação. A arte, assim, passa a influenciar os procedimentos da investigação, ou ser ela mesma um procedimento.

Quanto à tendência performativa, é importante destacar dois aspectos relevantes, um referente ao sujeito que pesquisa e outro referente à escritura. Em relação ao sujeito, “[...] a perspectiva performativa trata de gerar um novo sujeito de conhecimento, o sujeito performativo, que se constrói de forma fragmentada e descentrada" (HERNÁNDEZ, 2013, p. 53). Por isso, a 
experiência narrada é aquela em que o pesquisador está implicado, o que permite considerar que seja a sua própria experiência - autoetnografia. No que se refere à escritura performativa, existe uma preocupação na relação entre texto (verbal/visual), pesquisador e leitores/visualizadores. Essa escritura busca "[...] tocar o espectador, evocar emoções e proporcionar perspectivas alternativas de ver o mundo" (HERNÁNDEZ, 2013, p. 53, grifo do autor) - objetivos próprios e próximos das produções artísticas.

Embora possamos classificar as abordagens da PEBA em uma ou outra tendência, isso não significa que uma investigação explore de forma restrita os procedimentos de cada uma delas. É possível que uma investigação apresente elementos e procedimentos que extrapolem uma dessas tendências - uma espécie de hibridismo.

\section{A/R/TOGRAFIA COMO MÉTODO DA PESQUISA EDUCACIONAL BASEADA EM} ARTE

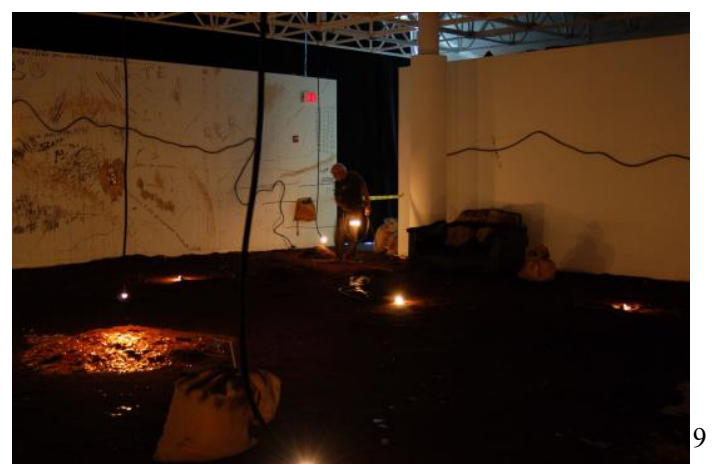

Viver a arte e o processo da pesquisa podem ser aspectos diferentes. No entanto, a obra de Barrio faz-nos pensar em tudo junto, em como ele se percebe artista, enquanto faz arte; como ele se faz artista; enquanto pesquisa a linguagem, o espaço, o contexto da arte. Assim, é possível pensar nessa proximidade de pensar o processo de se fazer pesquisa sobre arte, sobre educação e arte enquanto se faz arte e se pesquisa a poética do pesquisador.

Relacionada à PEBA, encontra-se a Pesquisa Baseada na Prática (PBP), que abrange métodos que se baseiam na prática artística. É especificamente aqui que localizamos a inserção da A/r/tografia na PEBA e visualizamos sua contribuição como uma das formas de pesquisa baseada

\footnotetext{
${ }^{9}$ Artur Barrio, Actions after actions (Ações após ações), 2006. Disponível em: <http://moore.edu/the-galleries-atmoore/exhibitions/exhibition-history/2006/artur-bario-actions-after-actions>. Acesso em: 22 maio 2017. 
no fazer artístico para a Educação, uma vez que, em termos gerais, a A/r/tografia é considerada um dos métodos de investigação possíveis, vinculados ao que se denomina Investigación Baseadas em las Artes.

A A/r/tografia constituiu-se em uma metodologia com seus principais conceitos e características, principalmente por meio do monitoramento de mais de trinta dissertações e teses de doutorado, realizadas entre 1994 e 2009 na Faculdade de Educação da University of British Columbia (UBC), em Vancouver, no Canadá. Os pesquisadores envolvidos nesse mapeamento buscaram, nesses estudos, aproximações e peculiaridades quanto às metodologias e aos métodos de pesquisar e ensinar envolvendo arte. Eles observaram que a A/r/tografia se estabeleceu como metodologia base para muitas dessas pesquisas, constituindo-se como uma prática de Pesquisa Educacional Baseada em Arte e também como uma Pedagogia (OLIVEIRA, 2013; DIAS, 2013; SINNER et al., 2013).

No Brasil, a discussão quanto à $\mathrm{A} / \mathrm{r} /$ tografia tem chegado, principalmente, por intermédio do professor Belidson Dias, da Universidade de Brasília, e da professora Rita Irwin, da University of British Columbia, pesquisadores que assinam algumas das primeiras publicações nacionais sobre A/r/tografia e tornaram-se referências no campo. Belidson Dias, por exemplo, contribui com textos sobre a $\mathrm{A} / \mathrm{r} /$ tografia que derivam da experiência vivida a partir de um projeto a/r/tográfico desenvolvido durante sua tese de doutorado, concluída em 2006.

Além de Belidson Dias e Rita Irwin, outros pesquisadores de universidades brasileiras e estrangeiras têm se dedicado à abordagem a/r/tográfica e contribuído com publicações na área em língua portuguesa, entre eles: Fernando Hernández, Irene Tourinho, Marilda Oliveira de Oliveira e Adriana Aguiar.

Se a A/r/tografia é um método de pesquisa que se baseia também na arte, o que difere a prática a/r/tográfica de outras formas de Pesquisa Educacional Baseada em Arte? Elas se referem à investigação mediante representações estéticas e artísticas. Já a prática a/r/tográfica situa a produção artística no centro do processo de investigação, ou seja, não há apenas a utilização de produções artísticas na investigação, mas o próprio desenvolvimento de práticas artísticas. Por meio de processos artísticos, busca-se problematizar, questionar, investigar e produzir conhecimento.

Enquanto outras formas de PEBA centram-se no resultado final, a A/r/tografia está preocupada em questionamentos por meio das artes, por isso é uma metodologia baseada na prática 
- fazer artístico. Assim, outras formas de PEBA dão importância à representação dos resultados, mas a A/r/tografia foca os entendimentos, os saberes e os conhecimentos conseguidos por intermédio dos processos e dos produtos artísticos desenvolvidos na investigação. Por isso, uma investigação a/r/tográfica investiga por meio de práticas e de atividades de artistas (IRWIN, 2013b).

O referencial epistemológico da A/r/tografia está inserido no construcionismo social - “[...] campo que se propõe a dialogar acerca da forma como concebemos o mundo, nos convidando a problematizar as realidades que são social e localmente construídas, tendo em vista o caráter subjetivo e cultural de cada sujeito" (OLIVEIRA, 2013, p. 1). Diferentemente das perspectivas epistemológicas que consideram a origem do conhecimento e da existência no Ser individual, a /ar/tografia compartilha da perspectiva de "[...] que a existência individual e o conhecimento são contingências de inter-relações com outros" (TOURINHO, 2013b, p. 236).

Esse apontamento traz o saber como um ato de construção. É um princípio que a A/r/tografia prevê - o conhecimento como criação - ao considerar que o conhecimento não é estático, depositado em um canto, esperando alguém possuí-lo, mas sim produzido por nossas percepções e reflexões - o saber como processo de criação. "Nós criamos ativamente o conhecimento mediante o intuir, o sentir e o pensar" (IRWIN, 2013a, p. 184). É por isso que, na A/r/tografia, o fazer artístico torna-se fundamental, pois é deste e por este que o conhecimento se constrói.

Pelo olhar de a/r/tógrafos, ou seja, os praticantes da $\mathrm{A} / \mathrm{r} /$ tografia, há necessidade de um deslocamento da concepção de um Ser que detém e transmite o conhecimento para o lugar de um ser que problematiza o conhecimento em espaços e tempos socialmente construídos. Contrariamente à influência do pensamento racionalista cartesiano, que sustenta a separação entre o sujeito que pesquisa e o objeto de pesquisa, separando corpo e mente, prática e teoria, as bases teóricas em que a $\mathrm{A} / \mathrm{r} /$ tografia se fundamenta vê o corpo em relação a outros corpos e não autônomo e isolado. A $\mathrm{A} / \mathrm{r} /$ tografia reflete um pensamento "[...] sobre ser(es)-em-relação e sobre comunidades de prática" (IRWIN; SPRINGGAY, 2013, p. 140). É um processo de intercâmbio que emerge da relação entre corpo e mente, de um eu e de um outro, por meio das interações com o mundo, sendo essa relação complexa o lugar de construção do conhecimento.

$\mathrm{O}$ a/r/tógrafo considera a sua vida profissional como um lugar de múltiplos e flexíveis papéis, pois não está interessado em fixar uma identidade, mas em viver papéis temporais. É nesse sentido 
que se justifica o acrônico a/r/t"10 (artist-researcher-teacher) e que se pode pensar em uma hibridização ou "mestiçagem” das incumbências desses profissionais (IRWIN, 2013b).

Essa hibridização ou mestiçagem de papéis temporais - artista, pesquisador e professor - é que provoca a produção de um "outro" tipo de conhecimento e permite vincular a A/r/tografia à Pesquisa Educacional Baseada em Arte. É por considerar a transitoriedade entre a prática de artistas, professores e investigadores que a $\mathrm{A} / \mathrm{r} /$ tografia se constitui em uma metodologia para a pesquisa em Educação, pois esses papéis provisórios vividos por este sujeito (professor-educadorinvestigador) permitem-no transitar de um a outro na busca de entendimentos do processo e dos produtos derivados dessa prática de investigação. Em uma perspectiva a/r/tográfica, teoria e prática não geram uma relação dicotômica, mas de encontro e de aproximações.

O movimento de artistas-pesquisadores-professores é em direção a formas de integrar saber, prática e criação. São três formas de pensamento e de identidades que não são sustentadas por um pensamento dicotômico, mas por um pensamento interligado e integrado, não hierarquizado. Considerando saber, ensino e criação, ou pesquisa, ensino e arte, os a/r/tógrafos movimentam-se em sistemas de categorias menos duais e mais complexas de intertextualidade e intratextualidade. As ações de pesquisar, ensinar e fazer arte costuram-se, entrelaçam conceitos, atividades, sentimentos e sensações e, na prática, configuram um tipo de síntese (IRWIN, 2013b).

Talvez, um dos princípios mais importantes que assegura essa relação da arte com a pesquisa seja a criatividade, especificamente no que se refere aos meios, aos métodos e aos processos que são utilizados (criados) ao se pesquisar. O caráter criativo das metodologias de pesquisa, da mesma forma que a experiência estética, intrínseca aos processos e aos produtos artísticos, “[...] integram ações processuais e relacionais que impactam nossas maneiras de ser e interagir com e no mundo, enquanto pesquisamos e ensinamos" (TOURINHO, 2013a, p. 65).

$\mathrm{Na}$ A/r/tografia, a criatividade coloca-se como elemento essencial, pois potencializa novas formas de pensar, de interpretar e de engajar-se em pesquisa e ensino - questões teóricas dos pesquisadores e práticas dos professores. Aqui, voltamos à perspectiva construcionista para considerar que pesquisar não está relacionado à busca de um "[...] estado final, ideal, que garanta êxito sobre qualquer assunto a ser estudado e ensinado" (TOURINHO, 2013a, p. 66), impedindo o aparecimento de interrogações ou desejos de ousadias, mas sim a um dado relacional. Relacional

\footnotetext{
${ }^{10} \mathrm{~A} / \mathrm{T} / \mathrm{R}$ é uma metáfora para o indivíduo que assume temporariamente os papéis de artista (artist), pesquisador (researcher) e professor (teacher). Hibridização marcada pela grafia (ghaph), entendida como escrita/representação. 
porque, embora ensinar e pesquisar estejam condicionados à escolha de temas, de métodos e de contextos, eles estão imbricados também “[...] com a capacidade de nos reinventarmos, enquanto pesquisadores e docentes, para fazer escolhas durante o processo e para encontrar maneiras de expor argumentos e questionamentos" (TOURINHO, 2013a, p. 66).

Trabalhar com incertezas e frustrações, repensar a dicotomia entre teoria e experiência, razão e emoção, são entendimentos necessários ao a/r/tógrafo, ou a um grupo de a/r/tógrafos. A defesa pela multiplicidade de caminhos reforça a metodologia como algo criado, processual e relacional, tornando um dos pressupostos da A/r/tografia a busca dessas possibilidades na e por meio da arte e da experiência estética. É sob esse olhar que se considera a "natureza rizomática" dessa metodologia. Certamente, a experiência do pesquisador vai sendo construída na sua prática profissional, o que é de extrema importância para a sua competência profissional. Entretanto, essa competência nunca é final ou totalizante, pois não há como impedir que, no decorrer dessas experiências, surjam interrogações e motivações para outros caminhos. Assim, a competência de pesquisadores deve ser entendida como "relativa e relacional" (IRWIN, 2013b).

A A/r/tografia provoca a abertura para a criação de um "terceiro espaço":

Teoria como a da a/r/tografia cria um momento imaginativo ao explicar os fenômenos por meio de experiências estéticas que integram saber, prática e criação: experiências que valorizam simultaneamente técnica e conteúdo por meio de atos de questionamento e experiências que valorizam complexidade e diferença em meio ao terceiro espaço. (IRWIN, 2013b, p. 129).

A A/r/tografia está preocupada com os meios, os processos, as formas de produzir conhecimento, e vê na arte mecanismos para isso, por isso centra-se no fazer artístico. No entanto, assim como outras formas de PEBA, a “[...] a/r/tografia é uma forma de representação que privilegia tanto o texto (escrito) quanto a imagem (visual), quando eles encontram-se em momentos de mestiçagem ou hibridização" (DIAS, 2009, p. 3.177).

Nesse sentido, os produtos artísticos originários do processo de investigação também compõem e se incorporam ao relato da investigação, ou podem eles mesmos se configurarem como relatos.

\section{CONSIDERAÇÕES FINAIS}



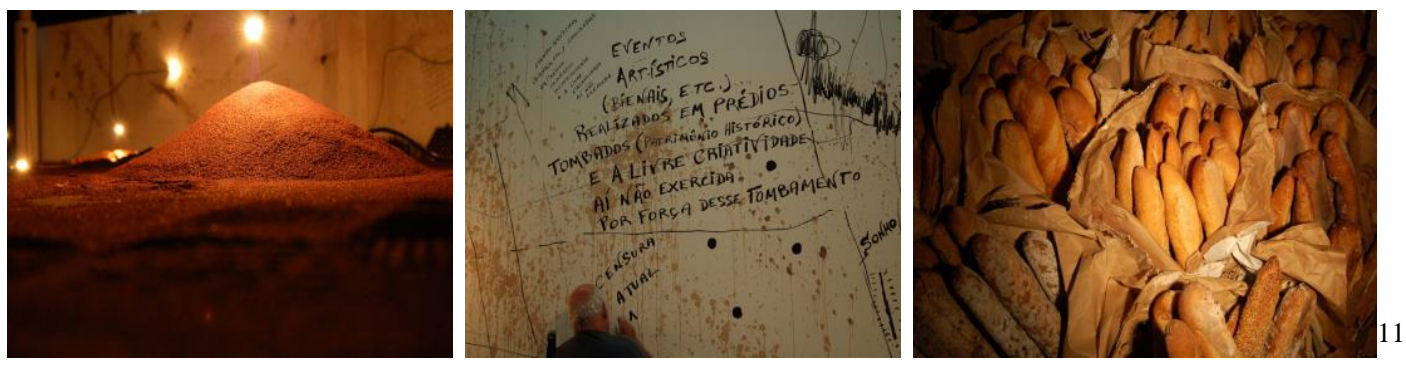

Detalhes do todo podem possibilitar-nos compreender parte do processo, discutir e dialogar com o todo da obra. Convida-nos a pensar e a tecer relações com a metodologia como processo criativo, que faz pensar enquanto se faz a pesquisa e a arte.

A PEBA, já sistematizada, apresenta-se como uma metodologia de investigação emergente para a pesquisa educacional no Brasil, especialmente porque as primeiras publicações sobre o tema em português não passam de uma década. Pelos estudos que fundamentam os aspectos epistemológico-metodológicos da PEBA e pelas publicações de relatos de experiências em pesquisa com essa metodologia, conforme apresentado neste texto, ela se mostra uma alternativa na superação da "metodolatria". Isso ocorre porque, ao aproximar arte, pesquisa e educação, bem como artistas, pesquisadores e professores, no caso específico da A/r/tografia, a PEBA evidencia a capacidade de inventar ao pesquisar e confronta os excessos de rigidez e de recomendações que tem permeado a ciência moderna. Excesso e rigidez das metodologias tradicionais que, talvez, têm dificultado a contribuição das pesquisas em Educação na (re)formulação de políticas educacionais e práticas educativas.

Por que a PEBA e a A/r/tografia podem promover uma intervenção diferente nas práticas e políticas na Educação? Talvez, porque tal perspectiva permite a pesquisadores, professores e estudantes envolverem-se em projetos a/r/tográficos, projetos teórico-práticos de conhecer que geram sentidos, significados e saberes, por meio do fazer artístico, e que, talvez, outros métodos não os evidenciem.

Entretanto, vale uma ressalva quanto à interpretação do emprego dessa metodologia para a pesquisa. Estudiosos advertem pesquisadores que se interessam em utilizar a PEBA e, assim, a A/r/tografia como metodologias em suas pesquisas que o rigor e as exigências às quais a produção de conhecimento científico está vinculada - como é o caso da pesquisa - não são excluídos por

11 Detalhes da obra de Artur Barrio. Actions after actions (Ações após ações), 2006. Disponível em: <http://moore.edu/the-galleries-at-moore/exhibitions/exhibition-history/2006/artur-bario-actions-after-actions > Acesso em: 22 maio 2017. 
essas metodologias. Desse modo, não é por se tratar de um trabalho com arte ou por meio da arte que poderão os pesquisadores eliminar aspectos como: elaboração de projetos, definição de aspectos metodológicos, de formatação e métodos, por exemplo.

Por fim, pontuamos que a PEBA e a A/r/tografia são metodologias contemporâneas de pesquisa. Dessa forma, o caminho ainda pode ser de muito trabalho para pesquisadores, professores e artistas que desejam ver a $\mathrm{A} / \mathrm{r} /$ tografia consolidada na pesquisa educacional no Brasil.

\section{REFERÊNCIAS}

BARONE, Tom; EISNER, Elliot. A Pesquisa Educacional Baseada nas Artes. Tradução: Leonardo Charréu (UFSM, Jun. 2013). In: GREEN, Judith; CAMILLI, Gregory; ELMORE, Patricia. Complementary methods in Educacional research. Nova Iorque: Lawrence Erlbaum Associates Inc., 2006. p. 95-103.

CARDOSO, Lívia de Rezende. Nos rastros de uma bruxa, compondo metodologias alquimistas. In: MEYER, Dagmar Estermann; PARAÍSO, Marlucy Alves. (Orgs.). Metodologias de Pesquisas Pós-Críticas em Educação. Belo Horizonte: Mazza, 2012. p. 219-241.

DIAS, Belidson. A/r/tografia como Metodologia e Pedagogia em Artes: uma introdução. In: DIAS, Belidson; IRWIN, Rita L. (Orgs.). Pesquisa educacional baseada em arte: a/r/tografia. Santa Maria: UFSM, 2013. p. 21-26.

DIAS, Belidson. Uma epistemologia de fronteiras: minha tese de doutorado como um projeto a/r/tográfico. In: ENCONTRO DA ASSOCIAÇÃO NACIONAL DE PESQUISADORES EM ARTES PLÁSTICAS - ANPAP, 18., 2009, Salvador. Anais... Salvador: ANPAP, EDUFBA, 2009. p. 3173-3187.

HERNÁNDEZ, Fernando Hernández. A pesquisa baseada nas artes: propostas para repensar a pesquisa educativa. In: DIAS, Belidson; IRWIN, Rita L. (Orgs.). Pesquisa educacional baseada em arte: a/r/tografia. Santa Maria: UFSM, 2013. p. 39-62.

IRWIN, Rita L. Visões e entrevisões: por uma estética de desdobramentos do currículo. In: DIAS, Belidson; IRWIN, Rita L. (Orgs.). Pesquisa educacional baseada em arte: a/r/tografia. Santa Maria: UFSM, 2013a. p. 183-195.

. A/r/tografia: uma mestiçagem metonímia. In: DIAS, Belidson; IRWIN, Rita L. (Orgs.). Pesquisa educacional baseada em arte: a/r/tografia. Santa Maria: UFSM, 2013b. p. 125-135.

IRWIN, Rita L.; SPRINGGAY, Stephanie. A/r/tografia como forma de pesquisa baseada na prática. In: DIAS, Belidson; IRWIN, Rita L. (Orgs.). Pesquisa educacional baseada em arte: a/r/tografia. Santa Maria: UFSM, 2013. p. 137-153. 
MEYER, Dagmar Estermann; PARAÍSO, Marlucy Alves. (Orgs.). Metodologias de pesquisas pós-críticas em educação. Belo Horizonte: Mazza, 2012.

OLIVEIRA, Marilda Oliveira de. Contribuições da perspectiva metodológica 'Investigação baseada nas artes' e da a/r/tografia para as pesquisas em educação. REUNIÃO NACIONAL DA ANPED, 36., 2013, Goiânia. Anais eletrônicos. Goiânia: UFG, 2013. Disponível em: <http://36reuniao.anped.org.br/pdfs_trabalhos_aprovados/gt24_trabalhos_pdfs/gt24_2792_texto. pdf>. Acesso em: 10 jul. 2015.

SINNER, Anita et al. Analisando as práticas de novos acadêmicos: teses que usam metodologias de Pesquisa Educacional Baseada em Arte. In: DIAS, Belidson; IRWIN, Rita L. (Orgs.). Pesquisa educacional baseada em arte: a/r/tografia. Santa Maria: UFSM, 2013. p. 99-124.

TOURINHO, Irene. Metodologia(s) de pesquisa em arte-educação: o que está (como vejo) o jogo? In: DIAS, Belidson; IRWIN, Rita L. (Orgs.). Pesquisa educacional baseada em arte: a/r/tografia. Santa Maria: UFSM, 2013a. p. 63-70.

TOURINHO, Irene. Aspectos e fragmentos de narrativas sobre o visual na prática educativa. In: DIAS, Belidson; IRWIN, Rita L. (Orgs.). Pesquisa educacional baseada em arte: $\mathrm{a} / \mathrm{r} / \mathrm{tografia}$. Santa Maria: UFSM, 2013b. p. 235-244.

Data de recebimento: $18 / 07 / 2017$

Data de aceite: 13/11/2017 